\title{
Gastric emptying and anaesthesia
}

Three major functions of the stomach are related to motility:

1 The muscles of the stomach relax to allow it to accommodate large volumes which may be ingested during eating and drinking.

2 When the muscles contract, the contents are mixed with gastric secretions allowing digestion to begin.

3 Organised contraction of muscles empties partially digested gastric contents from the stomach into the large bowel.

The stomach itself is not an important site for the absorption of water, nutrients or indeed any substance. The mucosa of the small bowel has such a larger surface area and it is the major site of absorption after oral administration. This applies to everything including food, liquids and nutrients but it is most striking for drugs. Virtually all drugs (acids, bases or neutral compounds such as ethanol or glucose) are absorbed much more rapidly from the small bowel than from the stomach. Therefore, it follows that the rate of gastric emptying is the rate-limiting step in the rate of absorption. Slow emptying delays absorption while rapid emptying accelerates absorption. Intra- or inter-individual variation in the rate or completeness of absorption of drug may result in part from variations in gastric emptying rate. Drugs which influence gastric emptying will, in turn, influence drug absorption.

\section{Importance of gastric emptying rate in anaesthesia} In the perioperative period, gastric emptying rate is important for three reasons:

1 If drugs are given orally, absorption may be erratic and delayed if gastric emptying is inhibited.

2 Delayed gastric emptying results in increased volume of gastric contents which may increase nausea and vomiting or delay the reinstitution of normal oral feeding and drug therapy.

3 Any increase in the volume of the acid gastric contents is likely to increase the risk of inhalation of these contents.

\section{Mechanics of gastric emptying ${ }^{1}$}

After eating, the stomach may contain more than one litre of contents with very little change in intragastric pressure because of relaxation of the proximal stomach to accom- modate the volume. Soon after eating, peristaltic waves are seen in the distal stomach and push the contents distally. The rate of emptying of liquids depends on the pressure gradient between the distal stomach and the duodenum but a marked increase in intragastric pressure does not necessarily indicate emptying as there may be an associated pyloric or other distal obstruction. Also, peristaltic waves may result in retropulsion.

Gastric emptying requires coordination of motility in the antrum, pylorus and duodenum. Modification or impairment of coordination by neural, hormonal or pharmacological influences may modify emptying without changing gastric muscle motility noticeably. Activity in the distal stomach has a specific role in the emptying of solid food and undigested particles but liquid may leave the stomach in the absence of antral contractions or muscle activity and its early emptying may be related to the rate of relaxation of the proximal stomach. It seems likely that when liquid is swallowed rapidly, there is a brief period when the resulting gastric distension is not matched by receptive relaxation. Gastric contents will escape under pressure through the pylorus if it is open. Normally, this volume is small, but it can be large after pyloroplasty or gastroenterostomy. In health, receptive relaxation matches the gastric distension and no emptying occurs until contractions begin. According to the relationship between receptive relaxation and gastric distension, the initial emptying of a liquid may be faster or slower than the rate which becomes apparent later. Both may occur in health.

Gastric emptying studies have shown that an exponential curve describes the data reasonably accurately. However, emptying is not truly exponential at the beginning and the end. Useful information may be missed if only the exponential curve is fitted.

\section{Measurement of gastric emptying rate re, $^{2,3}$}

Improved understanding of factors which change gastric emptying depends upon the techniques used for its measurement. Many approaches have been tried and so far none is ideal. Electrical activity and contractility of the stomach muscles are important but neither really reflects

Inveresk Clinical Research, Edinburgh and University of Edinburgh, Edinburgh, Scotland. 
gastric emptying rate and more direct measurement of emptying itself is required.

\section{Radiological methods}

Useful information can be obtained from conventional barium or gastrografin examination of the upper gastrointestinal tract but observations on gastric emptying rate are largely qualitative. Quantitative data are unreliable. In addition, barium itself may delay gastric emptying.

\section{Gastric aspiration methods}

The marker dilution method is accurate and reproducible but gastric intubation is unpleasant and may itself affect gastric motility through mechanical and physiological effects. It is applicable only to liquids and may be influenced by gastric secretions.

\section{Solute absorption methods $s^{4}$}

Because absorption of drugs and other solutes is negligible in the stomach compared with the small intestine, the rate of absorption after oral administration may be an indirect estimate of the rate of gastric emptying. Several different solutes have been used including glucose, ethanol and paracetamol. The test is noninvasive apart from blood sampling and it does not require large volumes of liquid to be swallowed. It has been used extensively in the perioperative period (see below).

\section{Scintigraphic methods}

A nonabsorbable gamma emitting radioactive isotope is incorporated into a test meal and the amount in the stomach is quantitated using an external gamma camera or scintiscanner on the abdomen. A series of measurements is made and the rate and pattern of emptying is defined. The noninvasive nature of this method increases the acceptability and avoids intubation.

\section{Ultrasound}

This is a noninvasive repeatable method which requires complex machinery but avoids the need for radioactivity. A series of cross-sectional scans along the long axis of the stomach is obtained and the volume computed using a video cassette recorder and a microcomputer.

\section{Electrical impedance}

If the test meal has different electrical conductivity from the surrounding tissues, a measure of the electrical impedance can be used to measure gastric emptying. Two different techniques are available - one uses only two pairs of electrodes (epigastric impedance) and the other uses 16 electrodes and creates cross-sectional images of the body based on tissue resisistivity (applied potential tomography ${ }^{3}$ ). Both these methods are noninvasive and
TABLE Factors which influence gastric emptying rate in the perioperative period

\begin{tabular}{|c|c|c|}
\hline & Increase & Decrease \\
\hline \multicolumn{3}{|l|}{ Physiological factors } \\
\hline Food & & ++ \\
\hline Large volume & ++ & \\
\hline Lying down & & ++ \\
\hline Neuroticism & + & \\
\hline Acid & & + \\
\hline \multicolumn{3}{|l|}{ Pathological factors } \\
\hline Pain & & \pm \\
\hline Pyloric stenosis & & $+t+$ \\
\hline Thyrotoxicosis & + & \\
\hline Hypothyroidism & & + \\
\hline Shock & & + \\
\hline \multicolumn{3}{|c|}{ Pharmacological factors } \\
\hline Opioids & & +++ \\
\hline Atropine-like drugs & & ++ \\
\hline Mist mag trisil & & ++ \\
\hline Metoclopramide & ++ & \\
\hline Domperidone & ++ & \\
\hline Cisapride & $+t$ & \\
\hline Propranolol & + & \\
\hline Alcohol & & ++ \\
\hline
\end{tabular}

convenient. It is necessary to prevent gastric acid secretion with cimetidine or ranitidine as acid in the stomach increases the gastric conductivity.

\section{Control of gastric emptying in man}

A summary of some important factors which influence gastric emptying and which are relevant to surgical patients is shown in the table.

Very few direct measurements of gastric emptying have been carried out in the perioperative period and several drug absorption studies have been used to estimate indirectly the effect of surgery and anaesthesia on gastric emptying rate.

\section{Physiological factors}

Food delays gastric emptying and liquids are emptied more rapidly than solids. Volume, $\mathrm{pH}$, temperature and osmotic pressure of the ingested solution influence the rate of emptying. Gastric distension is the only physiological stimulus known to accelerate emptying. Posture may influence emptying rate particularly in children - lying on the left side causes a delay.

\section{Pathological factors}

A variety of diseases may modify gastric emptying but not many direct measurements have been made. The most obvious and most marked delay is seen in patients with pyloric stenosis but other, non-gastrointestinal diseases may influence emptying. 


\section{Pharmacological factors}

The major cause of delayed gastric emptying and drug absorption before and after surgery is the administration of an opioid analgesic drug. The time to empty 50 per cent of an ingested solution from the stomach is increased eight- to ten-fold after meperidine or diamorphine. ${ }^{6}$ Gastric emptying may be inhibited completely for two hours after a large IM dose of diamorphine. This delay may not be reversed by metoclopramide, ${ }^{7}$ but delay induced by morphine is reversed by cisapride, a new gastric prokinetic drug. ${ }^{8}$

\section{Anaesthesia and gastric emptying}

Before surgery, in the absence of disease which may delay gastric emptying, emptying itself is normal unless the patient has received an opioid drug. Even in the presence of pain after trauma or in women during labour, there is evidence to suggest that gastric emptying is normal. ${ }^{7,9}$ This means that drugs given orally will be absorbed and that the volume of gastric contents may not be greater than expected for that patient unless he or she has received an opioid.

Gastric emptying rate is probably normal immediately after a short anaesthetic although a more prolonged procedure may result in some delay. Once again, the administration of an opioid analgesic drug is the major cause of delayed emptying after surgery. Extradural analgesia alone is associated with a much more normal pattern of emptying. ${ }^{10}$

Drugs which are normally absorbed rapidly and for whom the rate of absorption is important include analgesics, antiarrythmics and antibiotics. Delayed rate of absorption will result in delayed and perhaps lower peak concentrations which in turn will result in therapeutic failure. If these drugs are to be given orally in the perioperative period, the timing of administration should be as far removed from the administration of opioids as possible.

The effects of drugs which are normally absorbed more slowly and for which the extent of drug absorption is more important than the rate (e.g., digoxin, warfarin, corticosteroids) are not usually affected by changes in gastric emptying rate. Therefore these drugs may be given in the perioperative period without fear of failure of absorption.

For a very few drugs only, the extent of absorption is influenced by gastric emptying rate. These drugs include penicillin and 1-dopa which are unstable in gastric acid and may be broken down in the stomach.

\section{Conclusion}

An understanding of factors which influence gastric emptying rate is important for anaesthetists. In the absence of pyloric stenosis or other mechanical obstruc- tion to the gastric outlet, opioid drugs constitute the most important cause of delayed emptying in the perioperative period.

\section{References}

1 Nimmo WS. Effect of anaesthesia on gastric motility and emptying. Br J Anaesth 1984; 56: 29-36.

2 Sheiner HJ. Gastric emptying tests in man. Gut 1975; 16: 235-47.

3 Walker DAJ, Nimmo WS. New non-invasive methods for measuring gastric emptying. Br J Anaesth 1988; 60: 483-5.

4 Nimmo WS. Gastric emptying and drug absorption. In: Drug Absorption. Prescott, LF, Nimmo WS (Eds.). Adis Press, Auckland 11-20, 1979.

5 Nimmo WS. Drugs, diseases and altered gastric emptying. Clin Pharmacokin 1976; 1: 189-203.

6 Nimmo WS, Heading RC, Wilson J, Tothill, P, Prescott $L F$. Inhibition of gastric emptying and drug absorption by narcotic analgesics. Br J Clin Pharmacol 1975; 2 : 509-13.

7 Nimmo WS, Wilson J, Prescott LF. Narcotic analgesics and delayed gastric emptying during labour. Lancet 1975; $1: 890-3$.

8 Rowbotham DJR. Nimmo WS. Effect of cisapride on morphine induced delay in gastric emptying. $\mathrm{Br} J$ Anaesth 1987; 59: 536-9.

9 Marsh $R H K$, Spencer $R$, Nimmo WS. Gastric emptying and drug absorption before surgery. Br J Anaesth 1984; 56: 161-4.

10 Nimmo WS, Littlewood DG, Scott DB, Prescott LF. Gastric emptying following hysterectomy with extradural analgesia. $\mathrm{Br} J$ Anaesth 1978; 50: 559-61. 